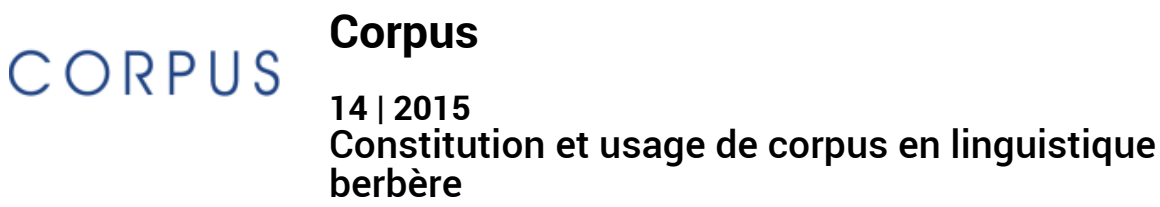

14 | 2015

Constitution et usage de corpus en linguistique berbère

\title{
Wh-Cliticisation: The derivation of operator- variable links and wh-words in Berber
}

Jamal Ouhalla and Abdelhak El Hankari

\section{(2) OpenEdition}

\section{Journals}

Electronic version

URL: http://journals.openedition.org/corpus/2686

ISSN: 1765-3126

\section{Publisher}

Bases ; corpus et langage - UMR 6039

\section{Printed version}

Date of publication: 1 January 2015

Number of pages: $235-262$

ISBN: 1 638-9808

ISSN: 1638-9808

\section{Electronic reference}

Jamal Ouhalla and Abdelhak El Hankari, « Wh-Cliticisation: The derivation of operator-variable links and wh-words in Berber», Corpus [Online], 14 | 2015, Online since 29 August 2017, connection on 08 September 2020. URL : http://journals.openedition.org/corpus/2686

This text was automatically generated on 8 September 2020

(C) Tous droits réservés 


\title{
Wh-Cliticisation: The derivation of operator-variable links and wh- words in Berber
}

\author{
Jamal Ouhalla and Abdelhak El Hankari
}

\section{Wh-clitic-doubling}

1 The phenomenon ${ }^{1}$ explored in this article can be seen in the Tamazight examples (1a\&b), with counterparts across Berber varieties, including Tashelhiyt (Radford, Felser and Boxell 2012) $)^{2}$. The examples are wh-questions where the operator-variable link corresponds to the dative argument (indirect object) of verbs such as 'give $\mathrm{x}$ to $\mathrm{y}$ ' and 'read $\mathrm{x}$ to/for $\mathrm{y}$.' Their most striking property is that they include two occurrences of wh. One is a wh-word situated to the left of the wh-Comp(lementiser) $a(y)$ in the position corresponding to Spec, $\mathrm{C}$. The other is a wh-clitic in the dative form situated to the right of the wh-Comp in the clitic-position associated with $\mathrm{C}$ (the CL2/C=CL position). We refer to this phenomenon as wh-clitic-doubling ${ }^{3}$.

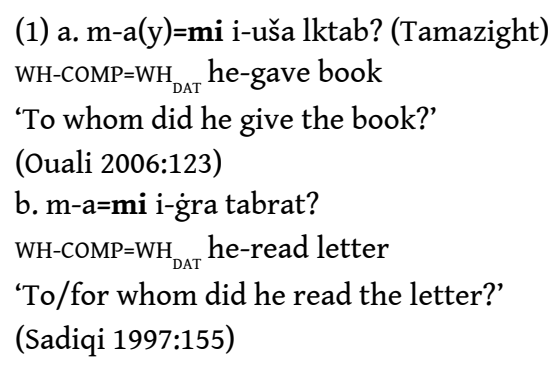

2 The wh-word to the left of wh-Comp is also prosodicaly dependent insofar as the Compcomplex $w h$-Comp $=w h_{D A T}$ is pronounced as one prosodic word. However, it is not a (syntactic) clitic because syntactic clitics are normally pro-clitics in Berber (Ouhalla 1988, 2005). For current purposes, we assume the distinction between prosodic clitics and syntactic clitics outlined in Klavans $(1980,1985)$ and subsequent literature. The 
former are a function of the mapping of syntactic structure onto prosodic structure and involve linear adjacency. Rightward attachment of the wh-word in Spec,C to the whComp $=w h_{D A T}$ complex is an instance of this process. Syntactic clitics are subject to displacement from the positions associated with their grammatical function. Displacement of the dative wh-clitic $=m i$ to $C$ is an instance of this process, referred to here as wh-Cliticisation and understood as an instance of Clitic Placement in the transformational sense of Kayne (1975). Syntactic clitics are designated with the symbol $=$.

3 Wh-clitic-doubling is found in other Berber varieties, although it may be partly hidden by prosody-driven processes that distort the underlying form of the Comp-complex. Example (2) is from Tashelhiyt and involves the extraction of a dative argument of a noun (possessor). The Comp-complex has broadly the same form, with Comp flanked by two wh-words, the second of which is the dative wh-clitic $=m i$. It differs in that the whComp has the form [ad] rather than [ay], which we take to be insignificant as far as the underlying pattern is concerned.

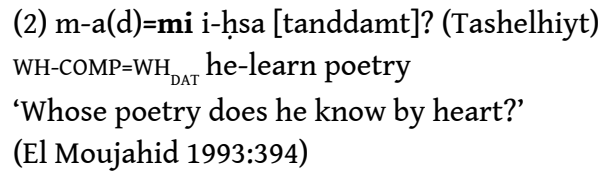

4 A slightly different situation is found in Tarifit. As shown in (3), the wh-Comp-complex has the form immi, which appears to lend itself to more than one analysis depending on how the morpheme $i$ - in the initial position is parsed.

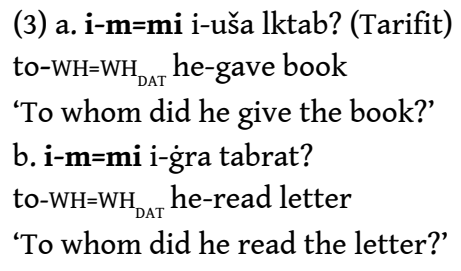

One possibility is that the initial $i$ corresponds to the wh-Comp $a(y)$, which is generally pronounced as [i(g)] in Tarifit (Cadi 2006, El Hankari 2010, Ouhalla 1988). This would mean that the Comp-complex has the form $i=m m i$, consisting of the wh-Comp $i(g)$ and a prosodically augmented form of the dative wh-clitic, but no wh-word corresponding to Spec,C. However, there are good reasons to exclude this parsing. Although null whwords corresponding to Spec, $\mathrm{C}$ are common in relatives (see below), this is not the case in wh-questions. Moreover, although the wh-word corresponding to Spec, C and Comps are subject to variation across varieties and operator-variable constructions (see below), the dative wh-clitic has a constant form and distribution across all constructions and varieties. The more plausible parsing is one where the vowel in the initial position is the dative preposition $i$ 'to' seen in the non-extraction contexts (4)(6). Accordingly, the Tarifit wh-Comp-complex has the form $i-m=m i$, which consists of the dative wh-PP $i-m$ 'to-wh' and the dative wh-clitic $=m i$, with a null Comp in between.

(4) uši-x lktab i-Fatima. (Tamazight)

gave-I book to-Fatima

'I gave the book to Fatima.'

(Ouali 2006:113) 
(5) i-ḥsa [tanddamt i -Sidi Ḥmmu]. (Tashelhiyt)

he-learn [poetry to -Sidi Ḧmmu]

'He knows the poetry of Sidi Hmmu.'

(El Moujahid 1993:396)

(6) uši-x lktab i -ufrux. (Tarifit)

gave-I book to -boy

'I gave the book to the boy.'

It is possible to abstract away from variation across varieties and assign the Compcomplex of operator-variable constructions a uniform underlying representation along the lines in (7). The constituent corresponding to Spec, $\mathrm{C}$ can be either a dative wh-PP of the form 'to-wh', as in Tarifit, or a non-Case-marked wh-word, as in Tamazight and Tashelhiyt. The Comp $a(y) / i(g)$ is subject to partial or total deletion subject to variation across constructions and varieties. The third constituent is the dative wh-clitic $=m i$ in the $\mathrm{C}=\mathrm{CL}$ position, which is not subject to deletion and has a constant form across varieties ${ }^{4}$.

$$
\text { (7) }\left[_ { C P } ( [ _ { P P } \text { to } ) [ _ { D P } w h ] ( ] ) \left[_{C^{\prime}}\left[_{C} a(y) / i(g)\right]=\left[w_{D A T}\right]\left[_{T P} \cdots\right.\right.\right.
$$

7 The Doubly Filled Comp Filter effects that manifest themselves in a complementary distribution between wh-words in Spec, $C$ and Comps are more evident in relatives. The Tamazight example (8) includes the relative Comp (re-Comp) $d a$ and the dative whclitic $=m i$, but lacks the wh-word corres-ponding to Spec,C. On the other hand, the Tashelhiyt and Tarifit examples (9)-(10) lack a re-Comp and instead include the whword corresponding to Spec, $\mathrm{C}$ in addition to the dative wh-clitic =mi. Whether this variation involves deletion or null categories or indicates the involvement of Headraising in some relatives (Kayne 1994) is irrelevant to current purposes. What is clear and crucially relevant is that all three examples show the dative wh-clitic $=m i$ in the $\mathrm{C}=\mathrm{CL}$ position.

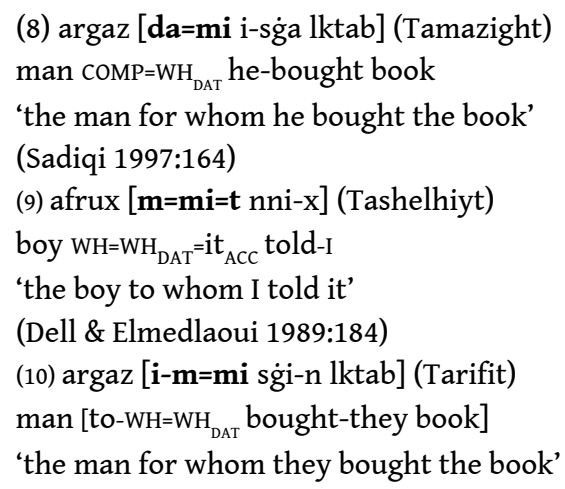

8 The situation in clefts is broadly the same, bearing in mind that clefts tend to share their Comp and other properties with wh-questions rather than relatives (11)-(13) (Cadi 2006, El Hankari 2010, Ouali 2006, 2011, Ouhalla 1988, Sadiqi 1982, 1997). Worth singling out is the Tarifit example in (13), where the cleft constituent appears in the dative form and the Comp-complex consists of the animate wh-word $u$ 'who' and the dative whclitic $=m i$, presumably separated by a null wh-Comp.

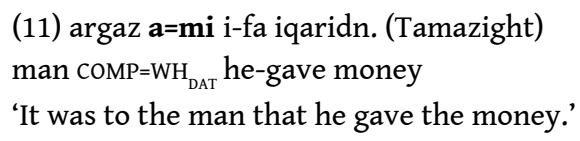




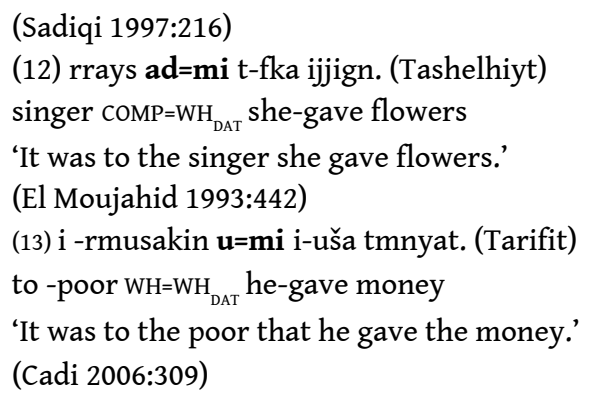

It is our judgement that the examples cited so far already contain sufficient information to exclude the possibility that the dative wh-clitic is a copy of the wh-word in Spec,C. This possibility arises in the context of the Copy Theory of Movement, whereby the extraction of arguments from within $v \mathrm{P}$ operates through the left-edge of $v \mathrm{P}$, where it leaves a copy that normally deletes (Chomsky 1995). According to this scenario, the dative wh-clitic would be the copy left on the edge of $v$ P by wh-Movement of the wh-word in Spec,C. The copy does not delete and instead cliticises to $\mathrm{C}$ for some reason. The two wh-constituents in wh-clitic-doubling are not exact copies of each other as can be seen in many examples above. The differences include the fact that while the dative wh-clitic is invariably in the dative form across varieties, the wh-word in Spec,C shows a dative marker in Tarifit, but not in Tamazight and Tashelhiyt. They also include the fact that the wh-word in Spec, $\mathrm{C}$ displays an animacy property in Tarifit but the dative wh-clitic does not. Moreover, it is unclear if and how Cliticisation of the copy to $\mathrm{C}$ is a substitute for deletion, particularly in view of the fact it brings the copy closer to the antecedent in Spec,C. Rather, dative wh-clitic-doubling shows the significant role of wh-Cliticisation to $\mathrm{C}$ in the derivation of operator-variable links. Its preponderance in Berber is a reflection of the fact that the language relies on whCliticisation (= derivational linking) rather than wh-Movement (Pied-piping) for extraction. This will become clearer as more data are examined ${ }^{5}$.

\section{Wh-Cliticisation}

It is tempting to treat dative wh-clitic-doubling as an instance of the more general phenomenon of dative clitic-doubling, avail-able across Berber varieties (Cadi 2006). Doubling by the dative pronominal clitic can be seen in (14)-(15).

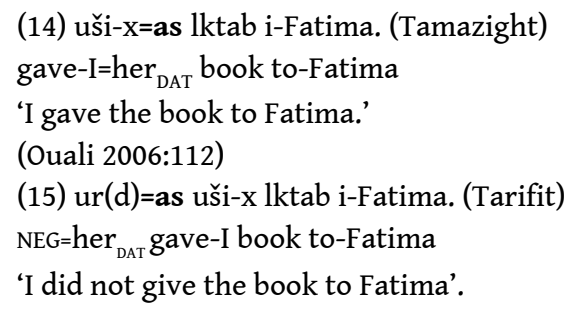

In view of the general availability of dative clitic-doubling, it is conceivable that dative wh-clitic-doubling is merely a manifestation of this more general phenomenon. The fact that the doubling clitic is of the wh-type in operator-variable constructions would follow from an Agree-based analysis of clitic-doubling of the kind outlined in Ouali $(2006,2011)$. When the dative complement is not a wh-phrase, it is doubled by a pronominal dative clitic (pronominal clitic-doubling), and when it is a wh-phrase, it is 
doubled by a wh-clitic (wh-clitic-doubling). Arguably, this analysis would correctly rule out doubling of a dative wh-phrase by a dative pronominal clitic in local contexts such as (16). These examples were previously considered in the context of resumption reduced to binding (Ouhalla 1993), but they can equally conceivably be considered as instances of a mismatch in a chain-link (Ouali 2006, 2011).

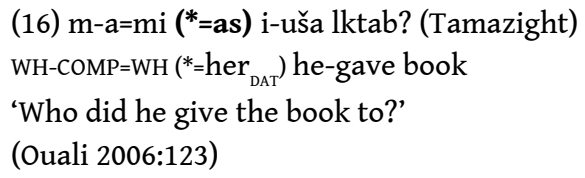

However, there are at least three major differences between the two types of dative clitic-doubling. First, while both constituents are in the dative form in pronominal clitic-doubling, only the wh-clitic is consistently in the dative form in wh-cliticdoubling in Tamazight and Tashelhiyt. Secondly, while dative pronominal cliticdoubling is optional (17a\&b), dative wh-clitic-doubling is obligatory in the sense that the presence of both wh-constituents is required, bearing in mind that relatives have a null wh-word in Spec,C.

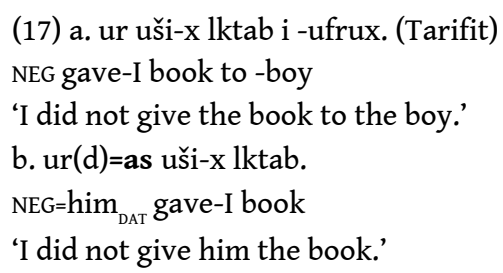

The third difference is more subtle and involves the clitic position targeted by pronominal clitics, including the dative one, compared to the clitic position targeted by the wh-clitic. A useful way of explaining this difference is to invoke a debate in the literature on Berber as to whether clitics and Cliticisation target a high position in the C-domain (Ouhalla 1988) or a lower position in the T-domain (Boukhris 1998, Sadiqi 1992). The latter view is based on, among other things, the rather straightforward fact that in sentences that include functional heads of the T-domain such as Tense and Negation, clitics appear to the right of these functional heads, as shown in (18a-b). The fact that clitics appear attached to a Comp element in sentences that do not include intervening functional heads in the T-domain such as (18c) is merely a (misleading) prosodic effect whereby the clitic seeks an adjacent prosodic host to its left. These contexts mask the fact that Cliticisation targets a lower position in the T-domain rather than a higher position in the C-domain.

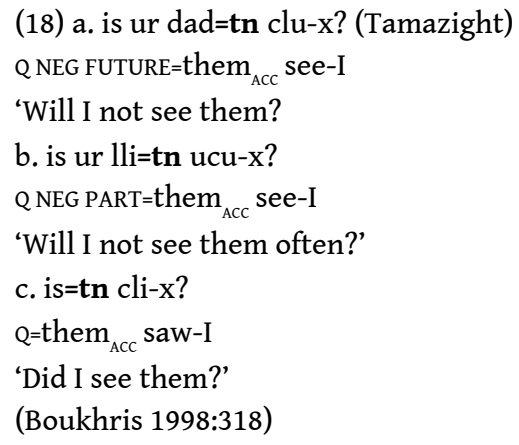


El Hankari (2012) undertakes an evaluation of both views and reaches the conclusion that they are both correct, but for different sets of data, more precisely, different sets of clitics. We will adopt this conclusion here, though from a different angle. We make a distinction between two types of clitics and Cliticisation. One type (A-clitics, ACliticisation) targets the T-domain, and mostly involves clitics linked to argument positions within VP but not to an operator in the C-domain. Typical examples of this type are the pronominal clitics in (17b) and (18a-c). The other type (A'-clitics, $A^{\prime}$ Cliticistion) targets the C-domain and involves clitics linked to an operator in Spec,C. The most notable example of this type is the dative wh-clitic, although there are others discussed below. As shown in the Tamazight example (19), the dative wh-clitic appears to the left of functional heads such as Tense and sentence Negation, suggesting that it targets the C-domain directly skipping over all intervening heads in the T-domain.

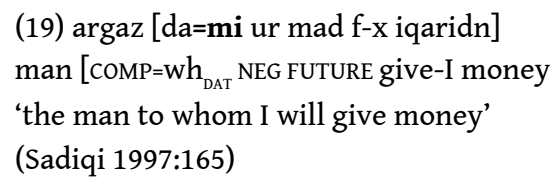

15 We conclude from the noted differences that dative wh-clitic-doubling is not reducible to dative pronominal clitic-doubling in general, while not excluding the possibility that there may be a significant link between the two instances of dative clitic-doubling. We will not pursue this line here as the focus is mainly on wh-clitic-doubling and operatorvariable constructions.

In view of the proposed classification of clitics and Cliticisation, the question whether Cliticisation is an instance of XP-Movement or Head-Movement (Kayne 1989) arises in an arguably stronger way. The possibility that Cliticisation involves a combination of XP-Movement followed by Head-Movement is conceivable on the view that clitics are heads that do not take a complement (i.e. they are both heads and XPs). A version of this mixed derivational scenario is applied to Berber in Boukhris (1998), whereby pronominal clitics move as XPs to the edge of $v \mathrm{P}$ and subsequently attach to the nearest functional head to their left, yielding the pattern seen in (18a-c). Extended to whclitics, the analysis could be understood to imply that their Cliticisation targets the edge of TP, placing them in a position from which they attach to the nearest constituent to their left, yielding the pattern seen in (19). According to this analysis, sketched in (20), Clitic Placement could conceivably be an instance of wh-Movement, in which case it would remain unclear why it does not target Spec,C instead. Stipulating that Spec,C is already filled with the other wh-word would amount to circular argumentation that fails to explain the essence of wh-clitic-doubling.

$$
\begin{aligned}
& \text { (20) }\left[_ { \mathrm { CP } } [ w h ] \left[_{C^{\prime}}, \mathrm{C}\left[_{\mathrm{TP}}=\left[\mathbf{w h} \mathbf{h}_{\mathrm{DAT}}\right]\left[_{\mathrm{TP}} \mathrm{Neg} / \mathrm{T}\left[_{\mathrm{WP}}\left(\mathbf{w w h}_{\mathrm{DAT}} \mathrm{T}\right)\right.\right.\right.\right.\right. \\
& {\left[{ } _ { v \mathrm { P } } v \left[\left[_{\mathrm{VP}} \ldots=\left[\mathrm{wh}_{\mathrm{DAT}}\right] \ldots\right.\right.\right.}
\end{aligned}
$$

The distribution of clitics in Berber is consistent with the view in Kayne (1989) that clitics move as heads and target head positions in the T-domain and C-domain. At the same time, the fact that the wh-clitic targets the C-domain directly, skipping over functional heads in the T-domain, clearly indicates that Cliticisation is not subject to the Head Movement Constraint (HMC). This would follow if Cliticisation = HeadMovement were feature-based and therefore discriminatory with respect to the head positions it targets. Presumably, the ability of the wh-clitic to target the C-domain 
directly is a function of the wh-feature it bears and shares with the C-domain of operator-variable constructions ${ }^{6}$.

(21) Cliticisation $=$ Feature-based Head-Movement

As far as wh-Cliticisation (Head Movement to C) is concerned, the justification for its existence in addition to wh-Movement turns out to rest on the fact that it applies in contexts that exclude wh-Movement (XP-Movement/Pied-piping to Spec,C), although it resembles wh-Movement in that is essentially a mechanism for deriving operatorvariable links. This is what transpires from a close examination of wh-clitic-doubling contexts.

\section{Dative objects of verbs and the dative wh-clitic}

El Moujahid (1993) and Sadiqi (1992) explicitly link the dative wh-clitic $=m i$ to the dative marker $i$ - 'to' seen in (4)-(6). El Moujahid (1993:395) and Cadi (2006:309) go one step further and gloss the dative wh-clitic as qui- $\grave{a}$, consisting of the wh-word $m$ 'wh' and the dative preposition $i$ 'to.' This analysis implies that $=m i$ is a PP-clitic, which is not implausible in view of the fact that Berber has PP-clitics on a productive basis and in fairly transparent forms (Boukhris 1998, Dell \& Elmedlaoui 1989, Ouhalla 1988). Berber PP-clitics can be pronominal, consisting of a preposition and a pronominal object clitic located in the T-domain, as in (22). They can also be of the wh-type, consisting of a preposition and a wh-object located in the C-domain of operator-variable constructions, as in (23a\&b). A more detailed discussion of wh-PP-clitics is included in the section on the extraction of objects of prepositions below.

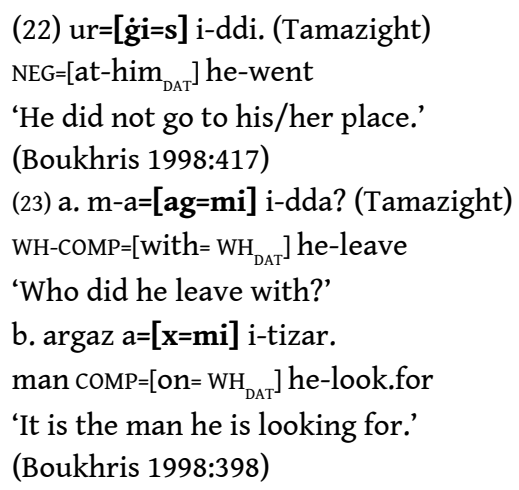

In view of the fact that Berber prepositions normally take their object to the right, the wh-P order implied by the analysis of the dative wh-clitic as a PP-clitic suggests a derivation whereby the wh-object undergoes wh-Movement to Spec,P suggested in Riemsdijk (1978) for wh-PPs where the wh-object precedes the preposition (e.g. English Who(did she leave) with?). However, there are compelling reasons to exclude the possibility that $=m i$ is a PP-clitic with an internal structure and derivation. They include the fact that wh-PPs normally have the P-wh order rather than the wh-P order, as shown in (23a\&b). This order is maintained in in-situ contexts such as (24) and (25). The reasons also include the fact that dative mi can appear as the object of a variety of prepositions, including dative preposition $i$ itself in (24).

(24) i-fa tabrat i-mi! (Tamazight) 


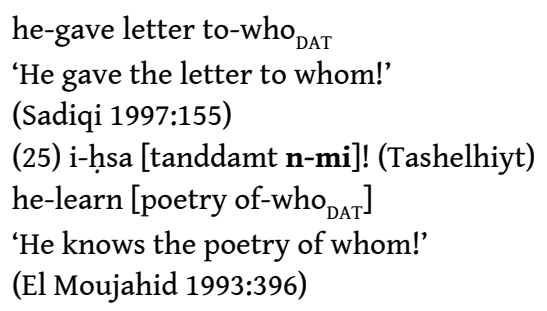

21 For current purposes, we will assume that dative $i$ is a Case-marker in the dative whclitic $=m i$ and $a$ preposition in other contexts ${ }^{7}$. Its presence in the dative wh-clitic indicates that it is specified for a Case-feature in addition to the wh-feature realised by the wh-morpheme $m$ along the lines shown in (26).

(26) The dative wh-clitic

$$
\left[_{\mathrm{DP}}\left[\mathrm{D}_{\mathrm{D}}=\mathrm{mi}_{[\mathrm{WH}, \mathrm{DAT}]}\right]\right]
$$

Given (26), the dative wh-clitic corresponds to an inherently Case-marked second argument (indirect object) of the verb in the examples repeated in (27) and (28). In contrast, the wh-word in Spec,C does not bear dative Case-marking in the Tamazight example (27).

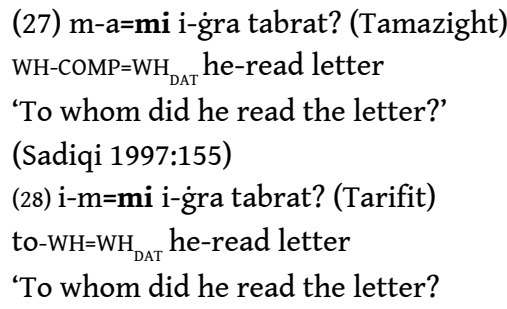

In view of the fact that it is the dative wh-clitic in the $\mathrm{C}=\mathrm{CL}$ position that consistently shows the Case of the extraction, variable site, it is plausible to conclude that the dative wh-clitic is the one that undergoes displacement from the dative position. If so, the whword in Spec, $\mathrm{C}$ must be base-generated in its surface position rather than moved there by wh-Movement as it is difficult to conceive of a derivational scenario that involves both wh-Movement to Spec, $\mathrm{C}$ and wh-Cliticisation to $\mathrm{C}$ at the same time. The possibility that the wh-word in Spec,C functions as a scope-marker, suggested for the upper occurrence of the wh-word in partial wh-Movement (Fanselow 2006), is unlikely in view of the fact that the wh-clitic in C shares essentially the same scope position. The alternative possibility that it functions as a wh-expletive (Horvath 1997), reducible to an EPP effect associated with C (Chomsky 1995), also appears unlikely in view of the fact that it shows the animate-inanimate distinction evident in the Tarifit example (13). The most likely possibility is that the wh-word in Spec,C functions as the operator that binds the variable in the dative position. The wh-clitic and wh-Cliticisation have the function of derivationally linking the wh-operator in Spec,C to the variable it binds. The derivation is shown in (29), which eschews the issue whether wh-Cliticisation out of $v \mathrm{P}$ involves the intermediate step of adjunction to $v \mathrm{P}$ on a par with wh-Movement.

$$
\text { (29) }\left[_ { \mathrm { CP } } [ \mathrm { wh } ] \left[_{\mathrm{C}^{\prime}} \mathrm{C}=\left[\mathbf{w h} \mathbf{D A T}_{\mathrm{DAT}}\right]\left[_ { \mathrm { TP } } \ldots \left[_{\mathrm{VP}} \text { read }\left[_{\mathrm{DP}} \text { letter }\right]\left[_{\mathrm{DP}}=\left[\mathbf{w h}_{\mathrm{DAT}}\right]\right] \ldots\right.\right.\right.\right.
$$

According to the analysis outlined in (29), wh-Cliticisation does the job that would otherwise require indexing, routinely assumed for (resumption) contexts where the operator is base-generated in its scope position. As such, wh-Cliticisation is in 
complementary distribution with wh-Movement, which applies in contexts where the operator is base-generated in the variable position and the operator-variable link is derived by wh-Movement of the operator to its scope position (Spec,C). These conclusions are summarised in (30a\&b).

(30) The derivation of operator-variable links

a) Wh-movement in contexts where the operator is base-generated in the variable position.

b) Wh-Cliticisation in contexts where the operator is base-generated in its scope position.

Berber is a language that makes use of the option of base-generating the operator in its scope position, possibly a function of the fact that its wh-words lack a Case-feature and therefore cannot be merged into Case/variable positions. This is more evident in Tamazight and Tashelhiyt than it is in Tarifit ${ }^{8}$. In contrast to wh-words, the wh-clitic clearly bears an additional dative Case-marker in all varieties. This contrast between frozen Caseless wh-words and the mobile dative wh-clitic will become more evident as more contexts of wh-clitic-doubling are discussed. These include contexts that involve so-called wh-words traditionally thought of as listed items that undergo wh-Movement. These wh-words turn out, on closer inspection, to have a compositional form that includes an occurrence of the wh-clitic. An early example is maymi 'why' reported in Cadi (2006) for a Tarifit dialect (31). This wh-word has pretty much the same form as the wh-Comp-complex in contexts that involve extraction of a dative argument of verbs such as (27). It is transparently analys-able as $m$-ay=mi corresponding to whComp $=w h_{D A T}$. Other dialects of Tarifit have a version of this wh-word that has the form mimi, where the Comp-constituent has the more familiar Tarifit form $m-i=m i$ ' whComp $=w h_{D A T}$.' Although it is unclear how the meaning 'why' arises, there seems little doubt that maymi/mimi is a wh-Comp-complex derived in the C-domain by whCliticisation of the dative wh-clitic to C, the Spec of which is filled by a base-generated wh-word.

(31) maymi i-ffg் ? (Tarifit)

why he-left

'Why did he leave?'

(Cadi 2006:299)

\section{Dative objects of prepositions and prepositional clitics}

As indicated above, Berber has wh-PP-clitics found in contexts that involve the extraction of the object of a preposition such as the ones repeated in (32a\&b). These wh-PP-clitics include the dative wh-clitic as the object of the preposition, consistent with the fact that objects of prepositions in general are in the dative form.

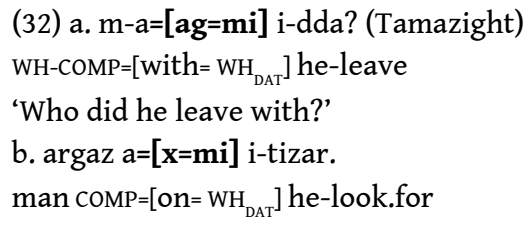


'It is the man he is looking for.'

(Boukhris 1998:398) This perceived link formed the basis for the derivational scenario outlined in Sadiqi (1982) and Ouhalla (1988), which assumes that the object of P is extracted by whMovement to Spec, $\mathrm{C}$ and the resulting problem of P-stranding, whatever it is, is dealt 
with by P-Cliticisation of stranded $\mathrm{P}$ to $\mathrm{C}$. However, the pattern in (32a\&b), overlooked at the time, suggests a simpler and more consistent derivational scenario, whereby $\mathrm{P}$ has a null wh-object recoverable under (partial) identity with the wh-word in Spec,C. The derivation is shown in (37) based on the Tarifit wh-question (36a), which is identical to the derivation in (34) apart from the fact that the wh-object of $\mathrm{P}$ is null. According to this analysis, seemingly bare $\mathrm{P}$ has the form $\mathrm{P}[\mathrm{wh}]$ and its Cliticisation to $\mathrm{C}$ is an instance of wh-Cliticisation ${ }^{9}$.

$$
\begin{aligned}
& \text { (37) }\left[_ { \mathrm { CP } } [ w h ] \left[_{C^{\prime}}[\mathrm{C}]=\left[\mathrm { C } _ { \mathrm { P } } \text { with } [ w _ { \text { bAT } } ] \left[_ { \mathrm { TP } } \ldots \left[_{\mathrm{VP}}\right.\right.\right. \text { sit }\right.\right. \\
& \mathrm{C}_{\mathrm{PP}} \text { with } \mathrm{E}_{\mathrm{DP}}=\left[\mathrm{wh}_{\mathrm{BAT}} \mathrm{H}\right. \text {... }
\end{aligned}
$$

The analysis outlined in (34) and (37) is consistent with and provides additional evidence for the conclusion here that Berber relies on wh-Cliticisation to $\mathrm{C}$ rather than wh-Movement to Spec, $C$ in the derivation of operator-variable links. The conclusion is equally reflected in the internal structure of some wh-words traditionally thought to be listed items, which on closer inspection turn out to include an occurrence of a P[wh]Clitic. The pattern that involves a wh-PP-clitic can be found in Tarifit mrmi 'when' seen in (38a), which includes an instance of the locative temporal preposition ar 'at/in' seen in (38b). This preposition is situated in a Comp-complex of the familiar form wh-Comp$w h_{D A T}$. Accordingly, Tarifit mrmi 'when' and the wh-questions that include it such as (37a) have the structure and derivation shown in (34). Rather than being listed, the socalled wh-word mrmi 'when' is assembled, derived in the C-domain and the temporal meaning reduces to something like 'at [time] what.'

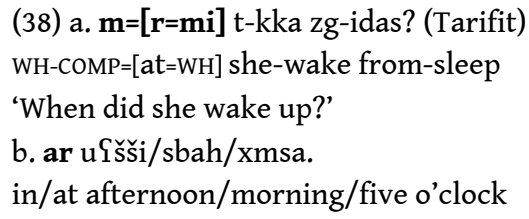

On the other hand, the pattern that involves a bare P can be found in the Tarifit whword mixf 'why' (39a) and arguably also maga 'why'. For example, mixf clearly incorporates the preposition $x(f)$ 'on/about' seen in (39b) in addition to the wh-Comp $i$ and the wh-word $m$ in the initial position. The Comp-complex has the familiar derived form $w h-C o m p=P$ such that the meaning 'why' is compositionally derived from the complex 'what on/about?' and possibly 'what for' for maga.

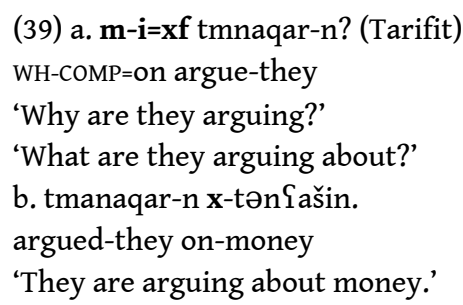

\section{Dative arguments of nouns (possessors)}

As indicated above, wh-clitic-doubling is found in contexts that involve the extraction of a dative argument of a noun (El Moujahid 1993). The relevant Tashelhiyt example is repeated in (40). 
(40) m-a=mi i-ḥsa [tanddamt]? (Tashelhiyt)

WH-COMP $=\mathrm{WH}_{\mathrm{DAT}}$ he-learned [poetry]

'Whose poetry does he know by heart?'

(El Moujahid 1993:394) appear either in the dative form or the genitive form, as shown in (41a-b), but only the dative form can be extracted. This is arguably more evident in focus-constructions such as (42a-b). In view of the fact that Berber makes use of wh-Cliticisation for extraction, the inability of the genitive form of possessors to extract can reasonably be thought of as a function of the fact that the language lacks genitive clitics (of the Romance type such as French dont). The exclusive reliance on wh-Cliticisation for extraction also accounts for the absence of the DP-pied-piping strategy used by various languages for the extraction of possessors, including Moroccan Arabic and English (e.g. šši $r$ dyal men hafed? Whose poetry does he know by heart?) on the reasonable view that pied-piping is an instance of wh-Movement.

(41) a. i-ḥsa [tanddamt i-Sidi Ḥmmu]. (Tashelhiyt)

he-learned [poetry to-Sidi Hัmmu]

'He knows Sidi Hmmu's poetry by heart.'

b. i-ḥsa [tanddamt $\mathbf{n}$-Sidi Ḥmmu]. (Tashelhiyt)

he-learned [poetry of-Sidi Hmmu]

'He knows Sidi Hmmu's poetry by heart.'

(El Moujahid 1993:395-6)

(42) a. i-Sidi Ḥmmu a(d) i-ḥsa [tanddamt].

to-Sidi Ḥmu comp he-learn [poetry]

'It is Sidi Hmmu's poetry he knows by heart.'

b. *n-Sidi Hmmu a(d) i-ḩsa [tanddamt].

of-Sidi Hmmu comp he-learn [poetry]

'It's Sidi Ḧmmu's poetry he knows by heart.'

(El Moujahid 1993:398-9)

Example (40) has the structure and derivation shown in (43), where the dative wh-clitic undergoes wh-Cliticisation from the possessor position inside DP to $C$ through $D$ (the escape hatch out of DP). Wh-Cliticisation through D is consistent with the fact that Berber lacks definite articles, although the question whether wh-Cliticisation out of DP operates through D needs closer examination than we are able to offer here.

$$
\begin{aligned}
& (43)\left[_ { \mathrm { CP } } [ \mathbf { w h } ] \left[_{\mathrm{C}^{\prime}} \mathrm{C}=\left[\mathbf{w h} \mathbf{h}_{\mathrm{DAT}}\right]\left[_ { \mathrm { TP } } \ldots \left[_{\mathrm{VP}}\right.\right. \text { learn }\right.\right. \\
& {\left[_{\mathrm{DP}}=\left[\mathbf{w h}_{\mathrm{DAT}}\right]\left[_{\mathrm{NP}} \text { poetry }=\left[\mathbf{w h}_{\mathrm{PAT}}\right] \ldots\right.\right.}
\end{aligned}
$$

Sadiqi (1997:166-7) discusses another possession context that gives rise to wh-cliticdoubling, shown in (44). This context differs in that it involves possessors of inalienable nouns such as 'man' = 'husband.' The Tarifit equivalent is given in (45a) along with an example that includes a body-part noun (45b).

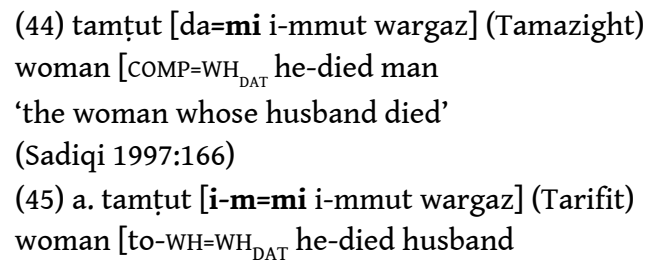


'the woman whose husband died'

b. i-m=mi qss-n azakuk?

to- $\mathrm{WH}=\mathrm{WH}_{\mathrm{DAT}}$ cut-they hair

'Whose hair did they cut?'

The additional examples in (46a\&b) show the possessor of the inalienable noun in the form of a pronominal clitic located in the T-domain. These are arguably the equivalent of French instances of external possession such as Le médecin leur a examiné la gorge discussed in Vergnaud and Zubizarreta (1992), which proposes a representational analysis that exploits a (predication) binding relation between the pronominal dative clitic and the inalienable object. In view of the broader context here, we will pursue a derivational account for the link between the possessor clitic and the inalienable object.

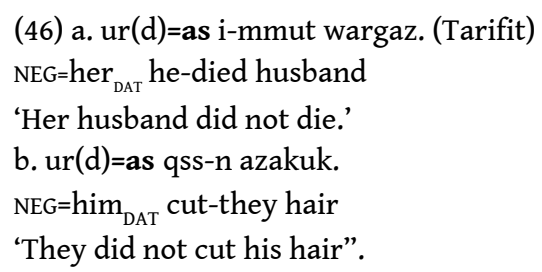

Focusing on the contexts that involve the extraction of the possessor, examples (44) and $(45 \mathrm{a} \& \mathrm{~b})$ have the derivation shown in (47).

$$
\begin{aligned}
& (47)\left[\left[_ { C P } [ \mathbf { w h } ] \left[\left[_{C^{\prime}} C=\left[\mathbf{w h}_{\mathrm{DAA}}\right]\left[\left[_ { \mathrm { TP } } \ldots \left[_{\mathrm{VP}}\right.\right.\right. \text { died }\right.\right.\right.\right. \\
& \left.\left[_{\mathrm{DP}}=\mathbf{w w h}_{\mathrm{PAT}}\right]\left[_{\mathrm{NP}} \text { husband }\left[_{\mathrm{DP}}=\mathbf{w h h}_{\mathrm{PAT}}\right]\right]\right] \ldots
\end{aligned}
$$

A useful aspect of this context is that it can be used to test if wh-Cliticisation is subject to constraints characteristic of syntactic movement, in particular those that fall under the heading of subject-object asymmetries. The outcome turns out to be familiar from Romance Cliticisation, in particular ne-Cliticisation in Italian (Burzio 1986). WhCliticisation of a possessor can operate out of arguments of unaccusative verbs such as 'die' in (44) and (45a) and direct objects of transitive verbs such as 'cut' in (45b), but not out of subjects of transitive verbs such as 'catch/arrest' in (48). The latter example is fine under the irrelevant benefactor reading 'the woman for whom the man caught the thief bearing in mind that argaz is ambiguous between the non-inalienable meaning 'man' and the inalienable meaning 'husband' and that benefactor arguments in general are in the dative form and therefore feed wh-cliticisation.

(48) tamțțut [i-m=mi i-țtf wargaz axwwan] woman [to- $\mathrm{WH}^{-} \mathrm{WH}_{\mathrm{DAT}}$ he-caught husband thief]

*'the woman whose husband caught the thief'

'the woman for whom the man caught the thief'

\section{Dative objects of verbs and objects of locative prepositions}

We saw above that wh-clitic-doubling is found in contexts that involve the extraction of the second dative argument of verbs such as 'read $\mathrm{x}$ for $\mathrm{y}$ ', 'give $\mathrm{x}$ to $\mathrm{y}$ ' and so on. Berber has a class of verbs that take a single argument in the dative form, the 
extraction of which also gives rise to wh-clitic-doubling. This class includes $\dot{g} r s$ 'slaughter', qqs 'sting', qqd 'burn' (Guerssel 1986), llf 'divorce,' ġms 'cover' (El Hankari 2010, Ouhalla 1988) and others with various idiosyncratic meanings (see below). As shown in the Tarifit examples (49a-d), with counterparts across Berber varieties, the single object of these verbs appears in the dative form, its corresponding pronominal clitic takes the dative form, and its extraction gives rise to wh-clitic-doubling. Close examination of this particular context reveals that it is reducible to the inalienable possession context.

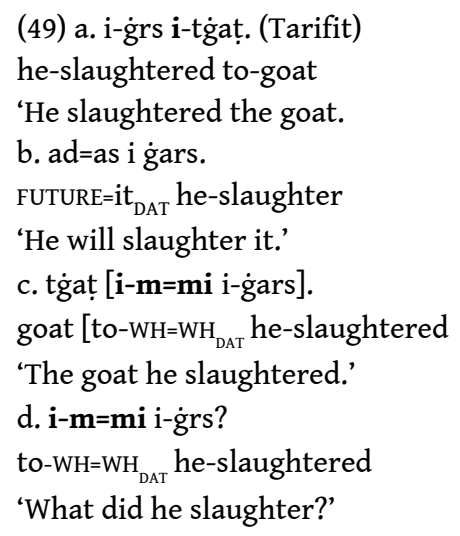

In his study of the lexical conceptual structures of various classes of verbs in Berber, Guerssel (1986) points out in connection to the verbs that take a single object in the dative form that they have more complex and precise meanings than can be rendered with English translations. For example, grs 'slaughter' has the more precise meaning 'kill by cutting throat,' which Guerssel suggests has the lexical conceptual structure repeated in (50). A close look at this structure reveals that what superficially appears as a dative object of the verb actually corresponds to the possessor argument of the understood body-part noun THROAT (e.g. 'cut [[throat] to-goat]]' in (49a)).

(50) LCS grrs: [x CUT THROAT y] (Guerssel 1986:45)

Guerssel (1986:45-46) illustrates this point further with an additional member of the class, namely $\mathrm{mrz}$ 'wound someone in the head.' Perhaps a more accurate rendition of the meaning of $m r z$ is 'wound x's HEAD,' where the body-part noun is HEAD and the human victim of wounding is the possessor of HEAD. This suggests the lexical representation roughly shown in (51) modelled on the one in (50), which includes the understood body-part noun HEAD ${ }^{10}$.

\section{(51) LCS mrz: [x WOUND HEAD y]]}

According to the analysis outlined in Guerssel (1986), the body-part component is lexically incorporated into the verb and consequently does not project as a syntactic constituent. A plau-sible slight variation on this analysis could exploit the mounting evidence for the presence of silent nouns in syntactic structures (Kayne 2005). According to this analysis, the verbs that take a single dative object project $v$ Ps of the form shown in (52), where the object includes a silent (body-part) noun that selects the 'dative object' as a possessor argument ${ }^{11}$.

$$
\text { (52) } \ldots\left[_ { \mathrm { vP } } \mathrm { x } \left[{ }_{\mathrm{VP}}\left[{ }_{\mathrm{V}} \text { WOUND }\right]\left[_{\mathrm{DP}} \mathrm{D}\left[\left[_{\mathrm{NP}}\left[\mathrm{C}_{\mathrm{N}} \mathrm{HEAD}\right][\mathrm{y}]_{\mathrm{DAT}}\right]\right]\right] \ldots\right.\right.
$$



mentioned points to a structure in line with more recent findings about locative prepositions across lan-guages (see contributions to Cinque \& Rizzi 2010). The structure is shown in (58) and takes the form of a PP headed by the directional preposition 'by' that takes a DP-complement headed by a place noun. According to this structure, what appears superficially as the object of preposition is actually the dative possessor of the place noun. Variation on this underlying structure revolves around whether locativedirectional P is overt, as in Tarifit, or null, as in other varieties.

$$
\text { (58) }\left[_ { \mathrm { PP } } s \text { 'by' } \left[_ { \mathrm { DP } } \mathrm { D } \left[_ { \mathrm { NP } } \left[_{N^{\prime}}\right.\right.\right.\right. \text { wadday '(the) under' }
$$




$$
\left.\left[{ }_{D P}=a s\right]{ }^{\prime i t}{ }_{\mathrm{DAT}}{ }^{\prime}\right] \ldots
$$

Berber is a language where wh-operators are base-generated in their scope position rather than the variable position, leading to a situation where it relies mostly, if not exclusively, on wh-Cliticisation for the derivation of operator-variable links. This is reflected not only in operator-variable contexts that involve dative constituents (arguments of verbs, nouns and prepositions), but also in various other contexts traditionally thought to involve listed wh-words. These turn out to have a compositional form that includes an occurrence of a wh-clitic, indicating that they are derived, assembled in the Comp-domain in syntax rather than listed in the lexicon.

51 Wh-clitic-doubling is a manifestation of the involvement of wh-Cliticisation (to C) in the derivation of operator-variable links. Wh-Cliticisation applies in contexts where the operator is base-generated in its scope position and has the function of linking the operator to the variable it binds. Wh-Cliticisation is in complementary distribution with wh-Movement (to Spec,C), which applies in contexts where the operator is basegenerated in the variable position, and where the operator-variable link is a function of wh-Movement. Wh-clitic-doubling and wh-Cliticisation amount to direct evidence for Cliticisation as an interpretive mechanism of Grammar that obviates the need for indexing (Chomsky 1995, Lebeaux 1983). They also amount to evidence for the conclusion in Kayne (1989) that Cliticisation is an instance of Head-Movement, more precisely, an instance of feature-based Head-Movement. 


\section{BIBLIOGRAPHY}

Achab K. (2003). “Alternation of state in Berber”, in J. Lecarme (ed.) Research in Afroasiatic Grammar Vol. II, 1-20. Amsterdam: John Benjamins.

Alami L. (in preparation). Word Order, Agreement and Resumption in the Tashelhiyt Variety of Berber, Ph.D. dissertation, University of Essex.

Aoun J. and Benmamoun E. (1998). "Minimality, reconstruction and PF movement", Linguistic Inquiry 29: 569-597.

Aoun J., Choueiri L. and Hornstein N. (2001), "Resumption, movement and derivational economy", Linguistic Inquiry 32: 371-403.

Bendjaballah S. \& M. Haiden. (2005). “The Grammar of Prepositions in Berber (Taqbaylit)”, LingBuzz/000261.

-. (2013a). "La représentation syntaxique des prépositions faibles du berbère de Chemini”, in J. Tseng (ed.) Prépositions et postpositions: approches typologiques et formelles. Paris: Hermès Lavoisier, 87-123.

-. (2013b). "The representational anomalies of floating markers: light prepositions in Taqbaylit of Chemini”, in T. Biberauer \& I. Roberts (eds) Challenges to Linearization. Berlin/New-York: Mouton de Gruyter, 331-375.

Bendjaballah S., S. Ben Si Saïd and M. Haiden. "Le syntagme prépositionnel à la périphérie gauche en Taqbaylit", in this volume.

Bošković Ž. (2001). On the nature of the syntax-phonology interface: cliticization and related phenomena, Amsterdam: Elsevier.

Boškovič Ž. (2002). “On multiple wh-fronting”, Linguistic Inquiry 33: 351-383.

Boukhris F. (1998). Les clitiques en berbère tamazight: approche minimaliste, PhD dissertation, Université Mohamed V, Rabat.

Burzio L. (1986). Italian Syntax, Dordrecht: Reidel.

Cadi K. (2006). Transitivité et diathèse en tarifit: analyse de quelques relations de dependences lexical et syntaxique, Rabat: Publications of the Royal Institute of the Amazigh Culture.

Chomsky N. (1986 a). “Barriers”, Linguistic Inquiry Monograph 13, MIT Press.

Chomsky N. (1995). The Minimalist Program, Boston: The MIT Press.

Cinque G. and L. Rizzi (eds.). (2010). Mapping Spatial PPs: The Cartography of Syntactic Structures, Oxford and New York: Oxford University Press.

Dell F. and Elmedlaoui M. (1989). "Clitic ordering, morphology and phonology in the verbal complex of Imdlawn Tashelhiyt Berber”, Langues Orientales Anciennes Phonologie et Linguistique 2: 165-194.

El Hankari A. (2010). The Morphosyntax of Tarifit Berber, PhD dissertation, The University of Queensland.

El Hankari A. (2012). “Agreeement, pronominal clitics and negation in Berber”, Brill's Annual of Afroasiatic Languages and Linguistics. A review of Ouali H. (2011). Agreement, Pronominal Clitics and Negation in Berber. London/New York: Continuum International Publishing Group. 
El Moujahid E. (1993). Syntaxe de groupe nominal en berbère tachelhiyt, Doctoral dissertation, University Mohamed V, Rabat.

Fanselow G. (2006). "Partial wh-movementV", in M. Everaert and H. van Riemsdijk (eds.) The Blackwell Companion to Syntax, Vol. III. 437-492. Malden, CA: Blackwell Publishing.

Guerssel M. (1986). “On Berber verbs of change: a study of transitivity alternations”, Lexicon Project Working Papers 9, Cambridge, MA: The MIT Press.

Guerssel M. (1987). "The status of the lexical category preposition in Berber: implications for the nature of the construct state", in M. Guerssel and K. Hale (eds.) Studies in Berber Syntax, Lexicon Project Working Papers 14, 159-190, Cambridge, MA: The MIT Press.

Halle M. and Marantz A. (1993). "Distributed Morphology and the pieces of inflection", in K. Hale and S. J. Keyser (eds.) The View from Building 20, 111-176, MIT Press.

Horvath J. (1997). "The status of 'wh-expletives' and the partial wh-movement construction of Hungarian", Natural Language and Linguistic Theory 15: 509-572.

Kayne R. (1975). French Syntax: The Transformational cycle. MIT Press.

Kayne R. (1989). “Null subjects and clitic-climbing”, in O. Jaeggli and K. Safir (eds.) The Null Subject Parameter 239-261. Dordrecht: Kluwer.

Kayne R. (1994). “The Antisymmetry of Syntax”, Linguistic Inquiry Monograph 25, MIT Press.

Kayne R. (2005). Movement and Silence, Oxford University Press.

Klavans J. (1980). Some Problems in a Theory of Clitics, Doctoral dissertation, University College London.

Klavans J. (1985). “The Independence of Syntax and Phonology in Cliticization”, Language 61, 95-120.

Lebeaux D. (1983). “A distributional difference between reciprocals and reflexives”, Linguistic Inquiry 14, 723-730.

McDaniel D. (1989). "Partial and Multiple Wh-Movement", Natural Language \& Linguistic Theory 7 , 565-604.

Ouali H. (2006). Unifying Agreement Relations: A Minimalist Analysis of Berber, Doctoral dissertation, The University of Michigan.

Ouali H. (2011). Agreement, Pronominal Clitics and Negation in Berber, London/New York: Continuum International Publishing Group.

Ouhalla J. (1988). The Syntax of Head-movement: A Study of Berber, PhD dissertation, University College London.

Ouhalla J. (1993). "Subject-extraction, negation and the anti- agreement effect", Natural Language and Linguistic Theory 11, 477-518.

Ouhalla J. (2001). "Parasitic gaps and resumptive pronouns", in P. W. Culicover and P. M. Postal (eds.) Parasitic Gaps 147-181, MIT Press.

Ouhalla J. (2005). "Clitic-placement, Grammaticalisation and Reanalysis in Berber", in G. Cinque and R. Kayne (eds.) The Handbook of Comparative Syntax 607-638, Oxford University Press.

Radford A., Felser C. and Boxell O. (2012). Preposition copying and pruning in present day English, Ms., University of Essex. 
Riemsdijk H. (1978). A Case Study in Syntactic Markedness. The Binding Nature of Prepositional Phrases, Dordrecht: Foris Publications.

Sadiqi F. (1982). A Syntactic Analysis of the Complex Sentence in Berber, PhD dissertation, University of Essex.

Sadiqi F. (1992). Issues in Berber cliticisation, Ms., University of Fès.

Sadiqi F. (1997). Grammaire berère. Paris: L'Harmattan.

Vergnaud J. R. and Zubizarreta M. L. (1992). “The definite determiner and the inalienable constructions in French and English”, Linguistic Inquiry 23, 595-652.

\section{NOTES}

1. This article first appeard in the journal IBERIA, Volume 4,2012 with the title 'Wh-cliticdoubling and Wh-Cliticisation'. We thank the publishers of IBERIA for granting permission to reproduce the article.

2. The Berber example cited in Radford, Felser and Boxell (2012) is sourced from Alami (in preparation).

3. We adopt a broad system of transcription of Berber data that aims at identifying the underlying forms of (function) words and morphemes abstracting away from general and dialectspecific phonological processes as much as possible. The French glosses and idiomatic translations in the original French sources of the Berber data have been replaced with English versions here. We take full responsibility for this.

4. To the extent that the proposed uniform structure of the Comp-complex of operator-variable constructions is plausible, we hope it justifies the reporting of some of the data here in an adapted form, where adaptation involves the parsing of the Comp-complex into its constituent morphemes. Comp-complexes are reported in the literature in various different ways that result in disguising underlying common patterns of the type sought here.

5. Wh-clitic doubling is partly reminiscent of the distribution of wh-words in multiple whquestions in some Slavic languages, where one wh-word is situated in Spec,C and the others in the CL2 position associated with C (Boškovič 2001, 2002). However, Berber wh-clitic-doubling differs in that it involves two occurrences of the same wh-word. As such, it is more reminiscent of partial wh-Movement (Horvath 1997, Fanselow 2006, Mc Daniel 1989). Here again, while partial wh-Movement is characteristic of long-distance extraction, wh-clitic-doubling is characteristic of local extraction. Long-distance extraction generally makes use of the resumptive strategy in Berber varieties such as Tamazight and Tashelhiyt (Boukhris 1998, El Moujahid 1993).

6. We will not address here the fact that syntactic clitics appear as enclitics on their host in Berber, which appears inconsistent with the claim in Kayne $(1989,1994)$ that clitics left-adjoin to their host. Ouhalla (1995) argues that the Berber facts are consistent with left-adjunction of clitics to their host once certain prosodic considerations of the language that distort this underlying order are taken into consideration (see also Ouali 2006, 2011).

7. Guerssel (1987) treats dative $i$ in 'to-DP' contexts as an instance of the category K(ase), which takes a DP as complement and can function as the object of prepositions along the lines shown in (i) (see also Achab 2003). To the extent that the analysis extends to the occurrence of dative $i$ in the wh-clitic $=m i$, it revives the possibility that the dative wh-clitic has an internal structure and derivation with KP in place of PP. This in turn leaves the 'to-wh' word order issue unresolved as for the PP-analysis. Although 'to-DP' contexts are treated as PPs here, we do not exclude the possibility that they are KPs.

(i) $\left[_{\mathrm{PP}} \mathrm{P}\left[{ }_{\mathrm{KP}}\right.\right.$ i 'to' $\left[_{\mathrm{DP}} \mathrm{D}\left[_{\mathrm{NP}}\right.\right.$ ufrux 'boy'] $\left.]\right]$ 
8. Since the first publication of the article, we have increasingly become aware that Tarifit is developing in a different direction relative to Tamazight and Tashelhiyt. Although it still shows remnant signs of derivation by Wh-Cliticisation, Tarifit appears to be moving towards derivation by Wh-Movement. Indications of this include dative Case-marking and animacy-marking of the wh-word in addition to the independently observed fact that Tarifit permits long-distance extraction, meaning does not require a resumptive pronoun in embedded contexts (Ouhalla 1988, 1993). Tamazight and Tashelhiyt differ in all three respects: they have a single wh-word which shows neither case-marking nor animacy-marking and do not permit long-distance extraction.We hope to explore this difference in a more systematic way in future research.

9. A third slightly different strategy of extracting objects of prepositions is reported for Chemini Taqbaylit in Bendjaballah, Ben Si Saïd and Haiden (this volumen) and Bendjaballah and Haiden $(2005,2013 a \& b)$.

10. Other instances of this class such as qqs 'sting', qqd 'burn' and gms 'cover' may involve the body-part noun BODY. This is indicated by the fact that qqd has the precise meaning of 'touching someone's body with a hot object such as a needle,' a method used in traditional healing.

11. Guerssel's (1986) analysis, which assumes lexical incorporation of a noun into the verb, is more suitable for other instances of such verbs such as Tarifit sfunzar, which has the meaning 'wound someone in the nose' or, more accurately, 'cause someone's nose to bleed.' The verb clearly incorporates the noun anzar 'nose' in addition to the causative prefix $s$ - and the morpheme $f(u)$ - the exact identity of which is unclear. The verb can be said to project the $v P$ shown in (i), which differs in that the body-part noun is overt rather than silent. The dative object is a possessor of the body-part noun. The verb $m r z$ too is likely to have the more precise meaning ' $x$ CAUSE [BLEED [HEAD [y $\left.]_{\text {DAT }}\right]$ ]' where the CAUSE component is abstract on a par with equally causative verbs with an abstract CAUSE such as trasnitive arz 'break,' qqn 'close,' arzm 'open' (Guerssel 1986).

(i) ... $\left[_{v P} \times\right.$ CAUSE $\left[{ }_{V P}\left[{ }_{V}\right.\right.$ BLEED $\left.]\left[{ }_{D P} D\left[_{N P}\left[{ }_{N} N O S E\right][y]_{D A T}\right]\right]\right] \ldots$

12. For derivational accounts that reduce resumption to movement in Syntax or at LF, see Aoun and Benmamoun (1998), Aoun, Choueiri and Hornstein (2001) and Ouhalla (2001).

\section{ABSTRACTS}

This article explores a phenomenon found in Berber whereby the extraction of dative arguments (of verbs, nouns and prepositions) gives rise to two occurrences of wh. One is a wh-word located in Spec, $\mathrm{C}$ and the other a wh-clitic in the dative form located in $\mathrm{C}$ (wh-clitic-doubling). Close examination reveals that the wh-word in Spec,C functions as an operator base-generated in its scope position and the dative wh-clitic in $C$ provides it with a derivational link to the variable in the dative position it binds (wh-Cliticisation). Wh-clitic-doubling and wh-Cliticisation amount to direct evidence for Cliticisation as a derivational interpretive mechanism of Grammar that obviates the need for indexing (Lebeaux 1983, Chomsky 1986, 1995). They also provide evidence for the conclusion in Kayne (1989) that Cliticisation is an instance of Head-Movement, more precisely, feature-based Head-Movement.

Cliticisation wh- : la dérivation des liens opérateur-variable et mots wh- en berbère Cet article explore un phénomène en berbère selon lequel l'extraction d'arguments datifs (de verbes, noms et prépositions) donne naissance à deux occurrences de wh. L'une est un mot wh 
situé en Spec,C et l'autre un clitique wh datif situé en C (redoublement de clitique wh). Un examen précis des données révèle que le mot wh en $S p e c, C$ fonctionne comme un opérateur généré directement dans sa position de portée et que le clitique wh datif en $\mathrm{C}$ lui fournit un lien dérivationnel avec la variable dans la position de datif qu'il lie (cliticisation wh). Le redoublement clitique wh et la cliticisation wh fournissent un argument direct pour l'interprétation de la cliticisation comme un mécanisme dérivationnel interprétatif de la grammaire qui rend inutile l'indexation (Lebeaux 1983, Chomsky 1986, 1995). Ils sont également des arguments en faveur de la conclusion de Kayne (1989) selon laquelle la cliticisation est une instance du mouvement de tête, plus précisément du mouvement de tête contrôlé par les traits.

INDEX

Keywords: wh-clitics, wh-clitic-doubling, wh-Cliticisation, wh-Movement, operator-variable links

Mots-clés: clitiques wh, redoublement de clitique wh-, cliticisation wh-, mouvement wh, relation opérateur-variable

\section{AUTHORS}

JAMAL OUHALLA

University College Dublin

ABDELHAK EL HANKARI

The University of Newcastle, Australia 